\title{
COMENTARIO DEL LIBRO: COSTA RICA DESPUÉS DEL CAFÉ. LA ERA COOPERATIVA EN LA HISTORIA Y LA MEMORIA, DE LOWELL GUDMUNDSON BOOK REVIEW: COSTA RICA DESPUÉS DEL CAFÉ. LA ERA COOPERATIVA EN LA HISTORIA Y LA MEMORIA, BY LOWELL GUDMUNDSON
}

Palabras claves: cooperativismo; café; Costa Rica; reseña; historia; historiografía; Lowell Gudmundson.

Keywords: Cooperative; Coffee; Costa Rica; Book Review; History; Historiography; Lowell Gudmundson.

\section{Introducción}

$\mathrm{L}$

a oportunidad de leer y comentar este valioso aporte de Lowell Gudmundson, ${ }^{1}$ para alguien que ha analizado la caficultura de Costa Rica, desde una perspectiva económica, es muy valiosa, pues valoro los aportes, al tener contacto con un análisis de la caficultura, desde la perspectiva históricosocial, que permite ampliar el panorama de análisis.

En particular, destaco la ventaja de entender las dinámicas en el más largo plazo, para entender y ubicar los fenómenos actuales. El libro parte con preocupaciones del presente inmediato de la sociedad costarricense, reflejadas en la dinámica de la caficultura. Por otra parte, destaco el aporte en términos de la nacional de Política Económica para el Desarrollo Sostenible (CINPE) de la Universidad Nacional (UNA), Costa Rica. Correo electrónico: rafael.diaz.porras@una.cr

1 Lowell Gudmundson Kristjanson, Costa Rica después del café. La era cooperativa en la historia y la memoria (San José, Costa Rica: Editorial Universidad Estatal a Distancia, 2018). 
integralidad del análisis, observando dinámicas políticas, sociales, productivas en Costa Rica, ubicadas en un contexto internacional, también de largo alcance.

Ello, se logra a partir del conocimiento que el autor tiene de la sociedad costarricense, por sus actividades de investigación y enseñanza, sobre la actividad cafetalera; con la ventaja de disponer de una mirada relativamente externa, desde los Estados Unidos, para entender las dinámicas de producción y consumo del café, y sus vínculos o determinantes de las sociedades.

\section{Las motivaciones del libro y la ruta que ofrece}

El autor inicia el libro, mostrando la motivación para escribirlo, que claramente nos muestra una preocupación compartida por generaciones nacidas entre 1950 y 1980. Gudmundson nos indica: "Presenciando los últimos acontecimientos en el otro país del cual somos ciudadanos y los temores que despiertan, dichas conversaciones en familia han reforzado nuestro compromiso de alertar a los lectores sobre lo que está en juego en nuestros días".

Esta es una preocupación no solamente analítica, en un desafío a clarificar, sino que también se liga con el nivel medio de la educación en nuestro país, con generaciones que viven en un entorno muy diferente al de la segunda mitad del siglo XX, viviendo y aceptando cambios en una sociedad, de la cual no conocen a profundidad sus raíces.

La ruta que nos ofrece el libro en sus cinco capítulos, nos lleva al primero que abre un gran panorama del contexto sociopolítico, en el cual, se desarrolla el cooperativismo en Corta Rica, para luego, a partir de los testimonios de informantes clave mostrar su nacimiento en dos localidades -Heredia y Tarrazú-, resultado de dos impulsos conjuntos, por una parte la necesidad de los productores de cambiar las relaciones mercantiles con su producción y por otra, el fomento estatal. En el capítulo III: "De revolución verde y grano de oro: memorias y metáforas de la generación fundadora", se recurre a la extracción de metáforas, a partir de las memorias de los fundadores del cooperativismo en los contrastes frente al cambio de la sociedad y en particular del papel de la caficultura en Costa Rica. En el capítulo IV: "Del reformismo cooperativo a la globalización gourmet: Java Joe, Juan Valdez, Starbucks y Café Britt", en una forma interesantísima, nos presenta la dinámica actual de la caficultura, con un sector en repliegue, reposicionándose hacia enfoques de calidad, que tienen un referente en las tendencias de mercadeo y consumo internacionales. A partir de estos elementos, el libro cierra con una revisión documentada de las consecuencias inesperadas, tanto para los productores del café, como para la sociedad costarricense, en las circunstancias de la Costa Rica reciente.

2 Ibíd., IX. 
A continuación, desarrollo mis reacciones ante algunas de las temáticas abordadas, que no son las únicas de mi parte, y que estoy seguro surgirán en multiplicidad desde diferentes ámbitos de la lectura.

\section{Populismo en perspectiva}

En el capítulo I: "Revolución verde como antídoto a la roja en la época verdiblanca: las cooperativas cafetaleras costarricenses y el reformismo anticomunista", se analiza la dinámica en la cual se ubica el desarrollo de las cooperativas cafetaleras en el proceso de reforma anticomunista, impulsado por el Partido Liberación Nacional. Se hace un abordaje desde la actualidad del populismo, aportando al entendimiento de hoy esta dinámica, característica de movimientos políticos, sean de derecha o de izquierda, descalificadoras de políticas de centro izquierda, con características similares a las observadas a principios del siglo XX, en los Estados Unidos, a lo largo de la Guerra Fría, a partir de la explotación de sentimientos nacionalistas, que culminan a partir de las posiciones de los gobiernos de Reagan con su clímax en el de Trump. Contrasta con el populismo costarricense de la década de 1940, donde, a diferencia de los fenómenos emblemáticos de Argentina con el peronismo, las bases fueron campesinas, en un ánimo reformista. El calderonismo fundado en una base obrera urbana y obrero agrícola de plantaciones bananeras, con el posterior desarrollo del figuerismo sustentados en una base campesina pequeña burguesa de productores cafetaleros, con la reivindicación del cooperativismo.

La confrontación llevó a lo que el autor denomina el reformismo competitivo, que permitió en Costa Rica el mantenimiento de la reforma social impulsada a partir del decenio de 1940, agregando el desarrollo del Estado de bienestar, impulsado por el Partido Liberación Nacional, llevando de la mano el florecimiento del cooperativismo, curiosamente, con un impulso en su nacimiento del gobierno no liberacionista de Mario Echandi.

Una afirmación importante en la lectura que realiza el autor refiere al hecho de que, frente a la discusión de mercado versus Estado, Costa Rica sostuvo "una dosis saludable de intervención del sector público". ${ }^{3}$

\section{La metodología}

En los capítulos II: "Informantes y antepasados heredianos: la generación fundadora en los registros censales y mortuales" y III -antes mencionado- se rastrea la generación fundadora del cooperativismo cafetalero en los casos de Heredia y Tarrazú, mediante un proceso combinado de análisis de registros censales y entrevistas. Un ejercicio desarrollado en el siglo XXI, localizando familias y personajes clave en la organización cooperativa pionera, a través del

3 Ibid., 29. 
testimonio de la generación viva, adulta mayor, con la memoria del proceso, y con la vivencia actual de la caficultura. Un proceso de florecimiento exitoso, y posterior declinación, a la luz de cambios sociopolíticos y económicos en los cuales la agricultura pasa a planos secundarios.

El recurso de la entrevista en busca de los relatos de memorias me parece destacable, por el conocimiento que se obtiene a partir de las trayectorias de los actores, en este caso los fundadores del cooperativismo, observándolos desde los tiempos fundacionales del cooperativismo, hasta su vida adulta mayor, que permite, desde sus sentimientos, observar los cambios personales y sociales.

\section{Impacto del cooperativismo cafetalero en el mercado}

En el recorrido mediante las memorias de los fundadores del cooperativismo, rescato algunos detalles que provoca el libro sobre el impacto en el mercado local de café. En primer lugar, un elemento movilizador para la organización cooperativa cafetalera lo constituyó el avanzar en la cadena. Los productores cafetaleros mantienen su propiedad individual, para avanzar hacia el beneficiado de café. En el lenguaje de las cadenas de valor esto es un escalamiento funcional. Ese fue el primer paso. Después, se ha intentado ir más allá en la exportación, no siempre con buenos resultados. Más recientemente, se presenta el acortamiento de la cadena a través de la búsqueda de ventas directas, y diversificación de productos con alguna torrefacción -desarrollo de marcas de café tostado y molido- y participación en el turismo -escalamiento intercadenas-.

Otro aspecto claramente observable en el libro se refiere al cambio que significó la presencia del cooperativismo en el mercado de café. Ello implicó que los beneficios privados tuvieran crecientemente como referencia, la acción de las cooperativas, logrando precios de liquidación atractivos, y agregando servicios a los productores. En muchos casos, en el nivel local-regional las cooperativas fueron las líderes de la competencia. Sin embargo, hubo un aspecto perjudicial a toda la actividad, cuando se pasó a una competencia por volumen, reduciendo los requerimientos de calidad del café recibido -incluyendo café verde-, y utilizando procesos en el beneficiado intensivos en el uso de agua, que le pasó la factura al sector, mediante las regulaciones ambientales que se le aplicaron al beneficiado, desde los alrededores de 1990. En ese contexto, los beneficios privados, en especial los que disponían de su propia exportadora compitieron con adelantos más altos, que coincidían con los precios de liquidación.

Sin embargo, el éxito cooperativista tuvo algunos límites. Cooperativas que quebraron a partir de la década de 1980, por liderazgos populistas que utilizaron la rentabilidad del negocio del café en servicios no rentables, incluso en el ámbito financiero. Como contraparte el surgimiento del oportunismo, por parte de los productores que diversificaban sus entregas de café entre su cooperativa y los beneficios privados, para obtener liquidez inmediata. Este detalle contrasta 
con el esfuerzo de los fundadores, quienes aportaron el capital semilla en la fundación de la cooperativa. Ese capital a lo largo de 20 años, ya no se constituía en una condición fuerte de entrada a las organizaciones.

\section{Contexto de la tendencia hacia la producción gourmet}

El capítulo IV del libro propone una muy ilustrativa discusión, desde esa intención del libro, ubicándonos en presente, pero entendiendo los procesos. Titulado el capítulo: "Del reformismo cooperativo a la globalización", se observa cómo el éxito cooperativo fue impulsado por las vicisitudes de la época en que funcionó en el Acuerdo Internacional del Café (AIC), y cómo, una vez finalizado este, en un proceso de liberalización, las empresas privadas pasan al desarrollo de un nuevo sistema de comercialización, basado en la calidad. El documento pasa a realizar un recuento de las tendencias en el consumo JAVA y Joe, así como de las estrategias emblemáticas de Juan Valdez, Starbucks y Café Britt. En este espacio no comentaré ilustrativos elementos del libro, sino que propongo aspectos que coinciden en la época reciente, y no mencionados con amplitud en el texto.

Tal como lo señala el texto, la regla de éxito inicial de las cooperativas fue la adquisición de plantas beneficiadoras, y la atracción masiva de nuevos socios, es importante destacar que el contexto de competencia entre beneficios en el ámbito nacional se modificó. Desde sus inicios el cooperativismo compitió con los beneficios privados, ligados a la oligarquía cafetalera, en la cual interactuaron los propietarios alemanes residentes en el país. Este esquema de competencia se extinguió a lo largo de la década de 1990, cuando los llamados beneficios privados fueron desapareciendo producto de la crisis y los problemas de financiamiento que enfrentaron. En el esquema que surgió, el espacio de los llamados beneficios privados pasó a ser multinacional, en la medida una parte importante de ese espacio lo ocuparon empresas como Volcafé y Ecom. Es una competencia de otras dimensiones, pues estas empresas incursionan en el beneficiado nacional, con la característica de operar en muchos países productores de café y con importantes vínculos en la cadena hacia adelante en la comercialización e industrialización internacional.

En este contexto, es que se desarrollan las tendencias que observamos actualmente, en lo que el autor llama el discreto encanto del buen gusto, propio del mundo posindustrial. Para cualquier estudioso del café este capítulo es un excelente y oportuno aporte, que muestra los elementos sociales explicativos del paso que sufre la industria cafetalera hacia el buen gusto. El análisis de las estrategias de Juan Valdez y Starbucks, este último masificando en los Estados Unidos el consumo del café gourmet, es un punto de referencia necesario. Y en esa dinámica, en el ámbito costarricense, el papel de Café Britt, que empresarialmente, no es resultado nacional, pero sí es una empresa que se desarrolla a partir 
de la caficultura nacional, con un impacto en el mercado de consumo interno, llevándolo hacia el gusto por el buen café, con una explosión de marcas, donde abundó inicialmente, la mención de $100 \%$ café, y posteriormente, la mención a los orígenes geográficos del café.

Hay dos temas complementarios en este movimiento hacia el café gourmet. Uno muy determinante lo fue la introducción de regulaciones ambientales al beneficiado de café en el decenio de 1990, que posicionó a la actividad desde una posición reactiva - pérdida de competitividad- hacia una posición proactiva, utilizando las mejoras en su perfil ambiental, como parte de la distinción del café costarricense. Esto ha llegado al punto de que este sector ha desarrollado el NAMA Café, una iniciativa en el contexto de los acuerdos internacionales sobre el cambio climático.

Un segundo aspecto por mencionar lo es el surgimiento del microbeneficiado en Costa Rica, por parte de productores de mayor tamaño, quienes en su afán de obtener mayor valor agregado han buscado diferenciar su producto, $y$ desarrollar vínculos comerciales más directos con los compradores. Es un proceso que en parte apoyó el Ministerio de Agricultura y Ganadería, a partir de un programa de sostenibilidad. Esta estrategia, en algún sentido, ha preocupado al cooperativismo, pues fragmenta disposición organizativa de los productores hacia esquemas empresariales individuales. Resultado de esto es que las posibilidades de conectarse con los nichos gourmet se han incrementado en mucho, por parte de este creciente sector-sobrepasan actualmente, los 300 microbeneficios- que, aunque en volumen siguen siendo pequeños, sí logran un impacto en términos de valor agregado.

\section{Las luchas diferenciadas y los resultados inesperados}

Un enlace importante entre el capítulo III, de memorias y metáforas, con el capítulo V: "Costa Rica después del café: transformaciones y consecuencias inesperadas", es la diferencia de la lucha cooperativista entre Heredia y Los Santos. En la primera parte, se da una lucha más confrontativa, donde los productores están en contacto con los beneficios privados, sintiendo la necesidad del cambio, y madurando el objetivo estratégico de contar con su propio beneficio. El libro contrasta con la situación más aislada de los productores de Tarrazú, donde la confrontación con los beneficiadores no se da en el grado que lo hizo en Heredia, donde los beneficiadores privados intentaron desalentar la iniciativa cooperativista.

Resultados inesperados: grandes productores y beneficiadores participando en las cooperativas, cuando declinan sus negocios. El otro contraste, el desarrollo urbano herediano sacando la actividad cafetalera de su geografía. En tanto que las zonas de expansión cafetalera, como Tarrazú pasan a ser el referente costarricense de su mejor café. 
En forma muy clara y con escritura hábil, el autor documenta los elementos que sorprenden a los cafetaleros, porque no los detectaron a tiempo, pero yo diría que sorprende no solo a los cafetaleros, sino al resto de la sociedad costarricense. Es el caso de la transición demográfica y los patrones sociales, donde los cafetaleros se envejecen, pero también la sociedad costarricense.

En este contexto se tiene la coexistencia de las migraciones, desde las zonas cafetaleras hacia Estados Unidos y de las zonas cafetaleras urgidas de mano de obra para la recolección del café. El patrón de las herencias que tendió a reducir tamaños de fincas entre herederos numerosos, el papel de las mujeres viudas en la gestión de los cafetales y el patrimonio familiar, y la tendencia actual de los herederos que no quieren ser cafetaleros, provocando lo que fue denominado por uno de los entrevistados como: la guerra del cemento y la tie$r r a$, que provoca la desaparición de los cafetales en el área metropolitana.

\section{Conclusión}

Este es un libro para ser leído. Escrito de una forma atractiva para el lector, con documentación muy seria y con un matiz vivencial destacable. Está impregnado de lo vivido por los actores del cooperativismo cafetalero, pero también del autor, su familia, los colegas de la Escuela de Historia de la Universidad Nacional, y a eso suma a quienes hemos vivido en la Costa Rica de esta historia.

Es un libro para ser estudiado, por la necesidad imperiosa de reflexionar con las nuevas generaciones que tienen el reto de transformar en democracia nuestras instituciones, entendiendo desde dónde provienen, separando cuidadosamente, los embates históricos que hacen olvidar los fundamentos de la sociedad solidaria, que es puesta en peligro por la forma en que la hemos operado, $o$ por las promesas de la eficiencia de mercados dominantes.

Destaco para finalizar, el gran desafío que plantea el autor: "El reto de nuestro tiempo, no sólo en Costa Rica, es reinventar el modelo de reforma para confrontar los nuevos desafíos de la creciente polarización y desigualdad". ${ }^{4}$

4 Ibid., 173. 
